\title{
Role of diabetes and obesity in outcomes of the candesartan antihypertensive survival evaluation in Japan (CASE-J) trial
}

\author{
Kazuwa Nakao ${ }^{1,2}$, Masakazu Hirata ${ }^{1}, K_{0 j i} \mathrm{Oba}^{2}$, Shinji Yasuno ${ }^{2}$, Kenji Ueshima ${ }^{2}$, Akira Fujimoto ${ }^{2}$, \\ Toshio Ogihara ${ }^{3}$ and Takao Saruta ${ }^{4}$, for the CASE-J Trial Group
}

The Candesartan Antihypertensive Survival Evaluation in Japan (CASE-J) trial assessed cardiovascular outcomes in high-risk hypertensive patients receiving either candesartan or amlodipine. The aim of this study was to examine the role of pre-existing diabetes or obesity on these outcomes as a sub-analysis of the trial. We examined the influence of pre-existing diabetes on cardiovascular morbidity and mortality using a multivariate Cox regression model. The cardiovascular morbidity and mortality of candesartan and amlodipine were compared between subgroups with or without pre-existing diabetes or by body mass index (BMI) category, and new-onset diabetes was compared by BMI category. Pre-existing diabetes greatly increased the cardiovascular mortality and morbidity, regardless of the allocated drugs. Furthermore, all-cause mortality was significantly higher with amlodipine than with candesartan among patients with BMI $\geqslant 27.5 \mathrm{~kg} \mathrm{~m}^{-2}$ (adjusted hazard ratio (HR) $=0.32$; range $=0.13-$ $0.75 ; P=0.009$ ). New-onset diabetes occurred significantly less frequently with candesartan than with amlodipine, with an adjusted HR of $0.66(P=0.043)$. Furthermore, the increase in new-onset diabetes was dependent on $B M I$ among patients receiving amlodipine, whereas no such dependency was observed for candesartan (interaction $P=0.016$ ). In conclusion, preexisting diabetes increased the risk of experiencing a cardiovascular event among high-risk Japanese hypertensive patients. Candesartan treatment may suppress all-cause death and reduce the incidence of new-onset diabetes in patients with obesity. Hypertension Research (2010) 33, 600-606; doi:10.1038/hr.2010.38; published online 9 April 2010

Keywords: cardiovascular diseases; diabetes; obesity; randomized controlled trial

\section{INTRODUCTION}

Hypertension is often associated with insulin resistance, and hypertensive patients tend to develop type 2 diabetes mellitus (DM), which increases the risk of cardiovascular (CV) events in these patients. Hypertension, insulin resistance, obesity and dyslipidemia frequently occur together in a single individual, and such clustering is recognized as metabolic syndrome. With the prevalence of obesity increasing worldwide, even in Asian nations, ${ }^{1}$ researchers have sought to develop treatment options capable of comprehensively addressing these risk factors in hypertensive patients.

As preexisting DM and obesity are thought to be related to the renin-angiotensin system (RAS), considerable interest has been focused on the difference between the treatment effects of angiotensin II receptor blockers (ARBs), angiotensin-converting enzyme inhibitors (ACEIs) and calcium channel blockers (CCBs) with regard to treating hypertensive patients with DM or obesity. Several large randomized clinical trials have found the therapeutic benefits from $\mathrm{ARBs},{ }^{2} \mathrm{CCBs}^{3,4}$ and $\mathrm{ACEIs}^{5}$ to be superior to beta blocker-based treatments or placebos with regard to reducing mortality and CV events in these patients. The Blood Pressure Lowering Treatment Trialists' Collaboration (BPLTTC) conducted an individual patient-based meta-analysis and concluded that all of the major classes of blood pressure (BP)lowering agents are capable of producing substantial reductions in short- to medium-term risk associated with the leading causes of death and CV events in patients with diabetes, although small differences in the effects of regimens on macrovascular events cannot be excluded. ${ }^{6}$ However, none of the previous trials have analyzed the relationship between obesity and antihypertensive treatment effects on cardiovascular outcomes.

With regard to new-onset DM, the ARB, valsartan, has been shown to suppress incidence of new-onset DM more effectively than the $\mathrm{CCB}$, amlodipine. ${ }^{7}$ We recently reported the principal results of the Candesartan Antihypertensive Survival Evaluation in Japan (CASE-J) study, a prospective, multi-center, open-label randomized controlled trial with blinded assessment of end points, which was designed to evaluate the efficacy of candesartan and amlodipine in reducing the

${ }^{1}$ Department of Medicine and Medical Science, Kyoto University Graduate School of Medicine, Kyoto, Japan; ${ }^{2}$ EBM Research Center, Kyoto University Graduate School of Medicine, Kyoto, Japan; ${ }^{3}$ Osaka General Medical Center, Osaka, Japan and ${ }^{4}$ Keio University School of Medicine, Tokyo, Japan

Correspondence: Dr K Nakao, Department of Medicine and Clinical Science and EBM Research Center, Kyoto University Graduate School of Medicine, 54 Shogoin-Kawaracho, Sakyo-ku, Kyoto 606-8507, Japan.

E-mail: nakao@kuhp.kyoto-u.ac.jp

Received 20 December 2009; revised 2 February 2010; accepted 3 February 2010; published online 9 April 2010 
incidence of CV morbidity and mortality in a Japanese population with high-risk hypertension. ${ }^{8}$ Although results ultimately showed no significant difference in incidence of $\mathrm{CV}$ events between the two treatments, ${ }^{9}$ of particular note among the findings was the fact that the ARB, candesartan, prevented new-onset DM more effectively than amlodipine, thereby raising the possibility that candesartan's treatment effect may be affected by obesity condition, given present knowledge regarding the mechanism of ARB action.

To clarify the role of preexisting DM and obesity in the findings of the CASE-J trial, we evaluated the influence of diabetic status and body mass index (BMI) on trial outcomes and the interaction between these factors and allocated treatments. Preliminary data have been described previously, ${ }^{9}$ and here we present a detailed post-hoc analysis.

\section{METHODS}

\section{Study design}

As the rationale and complete design of the CASE-J trial have been previously published, ${ }^{8}$ relevant details are briefly described below. For the trial, written informed consents were obtained from all patients before enrollment, and the trial protocol was approved by the ethics committee of Kyoto University and undertaken in accordance with the Declaration of Helsinki Principles. The data and safety monitoring board made periodic recommendations to the steering committee regarding the ethical aspects of trial continuation by evaluating each occurrence of a possible adverse event.

The CASE-J trial enrolled eligible Japanese hypertensive patients with, at least, one high-risk factor. High-risk factors in the CASE-J trial were as follows: severe hypertension that is systolic BP (SBP) $\geqslant 180 \mathrm{~mm} \mathrm{Hg}$ or diastolic BP (DBP) $\geqslant 110 \mathrm{~mm} \mathrm{Hg}$ on two consecutive visits; type $2 \mathrm{DM}$ (fasting blood glucose $\geqslant 126 \mathrm{mg}$ per $100 \mathrm{ml}$, casual blood glucose $\geqslant 200 \mathrm{mg}$ per $100 \mathrm{ml}$, hemoglobin Alc (HbAlc) $\geqslant 6.5 \%$, 2-h blood glucose on $75 \mathrm{~g}$ oral glucose tolerance test $\geqslant 200 \mathrm{mg}$ per $100 \mathrm{ml}$, or currently receiving treatment with a hypoglycemic agent); history of cerebral hemorrhage, cerebral infarction or transient ischemic attack occurring more than 6 months before screening; left ventricular hypertrophy on either echocardiography or electrocardiogram, angina pectoris or history of myocardial infarction occurring more than 6 months before screening; proteinuria or serum creatinine $(\mathrm{sCr}) \geqslant 1.3 \mathrm{mgper} 100 \mathrm{ml}$; and symptoms of arteriosclerotic peripheral artery obstruction.

After randomization, patients were allocated to receive either candesartan by oral administration at $4-8 \mathrm{mg} \mathrm{day}^{-1}$, increasing up to $12 \mathrm{mgday}^{-1}$ as necessary (or $2 \mathrm{mg} \mathrm{day}^{-1}$, increasing up to $8 \mathrm{mg} \mathrm{day}^{-1}$ as necessary in patients with renal impairment) or amlodipine by oral administration at $2.5-5 \mathrm{mg} \mathrm{day}^{-1}$, increasing up to $10 \mathrm{mg} \mathrm{day}^{-1}$ as necessary. Targets for BP control were determined according to practice guidelines developed by the Japanese Society of Hypertension (JSH), ${ }^{10}$ as reported previously. ${ }^{8}$

\section{Outcome measures}

Outcome measures evaluated in this analysis were CV event, non-renal CV event, all-cause death, CV death and new-onset DM. In the original CASE-J trial, $\mathrm{CV}$ event was the primary end point, which is the first fatal or non-fatal $\mathrm{CV}$ event and represented a composite of the following: sudden unexpected death that happened within $24 \mathrm{~h}$ without external causes; cerebrovascular events including stroke or transient ischemic attack; cardiac events including heart failure, angina pectoris or acute myocardial infarction; renal events, including $\mathrm{sCr} \geqslant 4.0 \mathrm{mg}$ per $100 \mathrm{ml}$, doubling of $\mathrm{sCr}$ (although $\mathrm{sCr}$ $\leqslant 2.0 \mathrm{mg}$ per $100 \mathrm{ml}$ in any context was not regarded as an event) and endstage renal disease; and vascular events, including dissecting aortic aneurysm or arteriosclerotic occlusion of a peripheral artery. As renal pathology in diabetic patients is affected by glycemic control, we also evaluated the incidence of nonrenal CV events that excluded renal events from primary CV events. All-cause death and new-onset diabetes were the secondary and pre-specified end point in the CASE-J trial. Event evaluation for CV event and all-cause death was independently performed by the event evaluation committee members, who were blinded to the assigned treatment groups and assessed events according to the protocol criteria. Cases of new-onset DM were defined as patients who were reported to have developed DM as an adverse event or who were on anti-diabetic agents during the course of the study as reported in the case report form.

\section{Statistical methods}

Baseline characteristics were expressed as mean \pm s.d. or proportions, and between-groups using the $\chi^{2}$ test or $t$-test. Analyses were divided into two parts: we first evaluated the influence of preexisting DM at baseline on each end point as a prognostic factor analysis. Here, we conducted multivariate Cox regression analysis with adjustment for allocated drugs, BMI, age, sex, hyperlipidemia, smoking history, high-risk factors in the CASE-J trial (severe hypertension, cerebrovascular history, cardiac complications, renal dysfunction and vascular disease) and antihypertensive drug use at baseline.

We then conducted a comparison with regard to allocated drugs (candesartan vs. amlodipine) across subgroups for baseline presence or absence of preexisting DM and the BMI category $(<22.0, \geqslant 22.0-25.0, \geqslant 25.0-<27.5$ and

Table 1a Baseline characteristics in patients with and without diabetes ${ }^{\mathrm{a}}$

\begin{tabular}{|c|c|c|c|c|c|c|}
\hline & $\begin{array}{l}\text { Candesartan } \\
(\mathrm{N}=1011)\end{array}$ & $\begin{array}{l}\text { Amlodipine } \\
(\mathrm{N}=1007)\end{array}$ & P-value & $\begin{array}{l}\text { Candesartan } \\
(\mathrm{N}=1343)\end{array}$ & $\begin{array}{l}\text { Amlodipine } \\
(\mathrm{N}=1342)\end{array}$ & P-value \\
\hline Age (years) & $63.9 \pm 9.5$ & $64.1 \pm 9.9$ & 0.660 & $63.6 \pm 11.2$ & $63.8 \pm 11.7$ & 0.684 \\
\hline BMI $\left(\mathrm{kg} \mathrm{m}^{-2}\right)$ & $25.1 \pm 3.9$ & $25.1 \pm 3.6$ & 0.739 & $24.2 \pm 3.5$ & $24.0 \pm 3.5$ & 0.099 \\
\hline Female (\%) & $445(44.0)$ & $447(44.4)$ & 0.866 & $647(48.2)$ & $567(42.3)$ & 0.002 \\
\hline Cardiac complications ${ }^{\mathrm{b}}(\%)$ & $291(28.8)$ & $313(31.1)$ & 0.260 & $716(53.3)$ & 710 (52.9) & 0.833 \\
\hline Renal dysfunction ${ }^{\mathrm{b}}(\%)$ & $228(22.6)$ & $216(21.5)$ & 0.550 & $344(25.6)$ & $327(24.4)$ & 0.455 \\
\hline Vascular disease (\%) & $11(1.1)$ & $5(0.5)$ & 0.134 & $18(1.3)$ & $19(1.4)$ & 0.867 \\
\hline Antihypertensive drug use (\%) & $712(70.4)$ & $686(68.1)$ & 0.262 & $900(67.0)$ & $867(64.6)$ & 0.188 \\
\hline Current or smoking history (\%) & $319(31.6)$ & $319(31.7)$ & 0.952 & $386(28.7)$ & $474(35.3)$ & $<0.001$ \\
\hline Hyperlipidemia (\%) & $460(45.5)$ & $440(43.7)$ & 0.415 & $608(45.3)$ & $570(42.5)$ & 0.144 \\
\hline
\end{tabular}

Abbreviations: BMI, body mass index; DBP, diastolic blood pressure; DM, diabetes mellitus; SBP, systolic blood pressure.

aData are shown as the mean \pm s.d. or $n(\%)$ in each category.

bSevere hypertension (blood pressure $\geqslant 180$ or $\geqslant 110 \mathrm{~mm} \mathrm{Hg}$ ), cerebrovascular event history (history of stroke or transient ischemic attack), cardiac complication (left ventricular hypertrophy, angina pectoris or history of myocardial infarction), renal dysfunction (proteinuria or serum creatinine $\geqslant 1.3 \mathrm{mg}$ per $100 \mathrm{ml}$ ). 


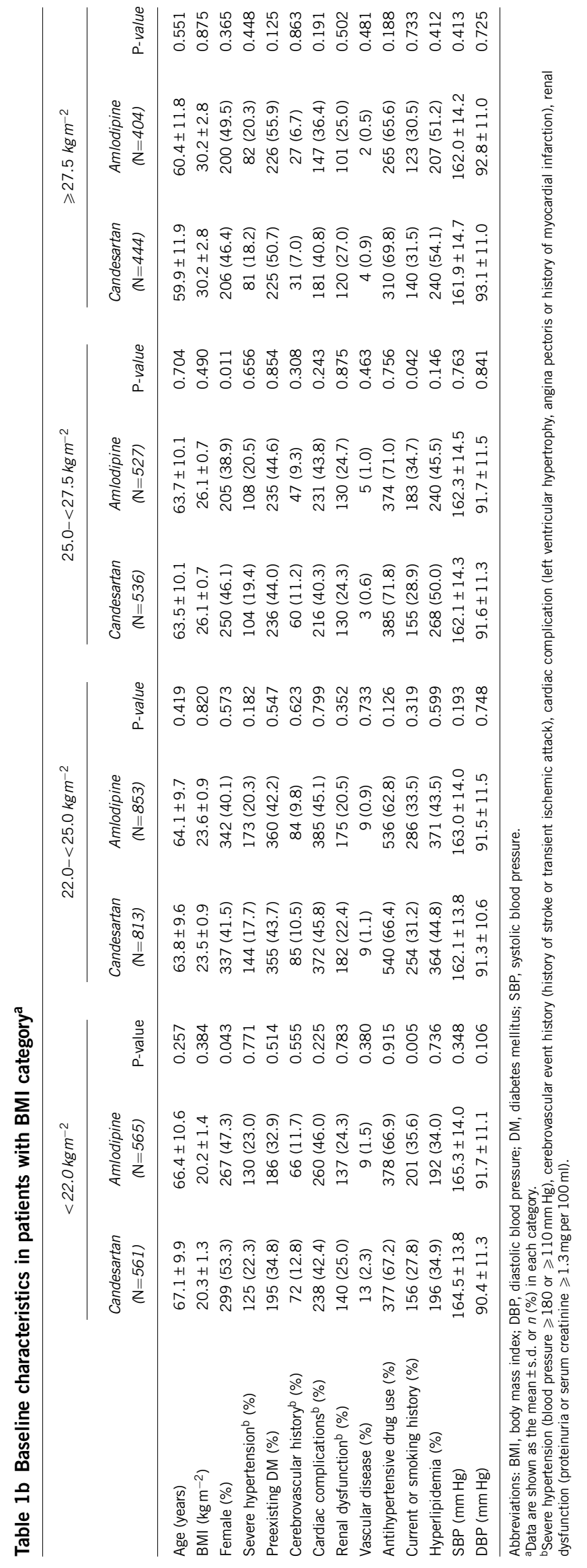

Table 2 Adjusted HRs of prognostic factors for primary CV events

\begin{tabular}{lccc}
\hline Baseline characteristics & $H R^{a}$ & $95 \% \mathrm{Cl}$ & P-value \\
\hline DM (present) & 2.58 & $1.99-3.33$ & $<.001$ \\
Allocated drugs (candesartan) & 0.99 & $0.78-1.26$ & 0.922 \\
Age & 1.37 & $1.19-1.57$ & $<0.001$ \\
BMI & 1.16 & $0.98-1.37$ & 0.092 \\
Sex (female) & 0.89 & $0.67-1.18$ & 0.411 \\
Severe hypertension (yes) & 1.10 & $0.74-1.65$ & 0.632 \\
Cerebrovascular history (yes) & 2.04 & $1.47-2.83$ & $<0.001$ \\
Cardiac complications (yes) & 2.21 & $1.72-2.84$ & $<0.001$ \\
Renal dysfunction (yes) & 2.93 & $2.30-3.74$ & $<0.001$ \\
Vascular disease, yes & 1.68 & $0.69-4.10$ & 0.255 \\
Antihypertensive drug use at baseline (yes) & 1.42 & $1.05-1.91$ & 0.024 \\
Current or former smoker (yes) & 1.02 & $0.77-1.36$ & 0.871 \\
Hyperlipidemia (yes) & 0.89 & $0.69-1.15$ & 0.368 \\
\hline
\end{tabular}

Abbreviations: $\mathrm{BMI}$, body mass index; $\mathrm{Cl}$, confidence interval; $\mathrm{CV}$, cardiovascular; DM, diabetes mellitus; HR, hazard ratio.

aThe HR value was adjusted for all baseline variables listed in Table 2 entering in the multivariate Cox regression model.

$\left.\geqslant 27.5 \mathrm{~kg} \mathrm{~m}^{-2}\right)$. The cutoff points of the BMI category $\left(22 \mathrm{~kg} \mathrm{~m}^{-2}\right.$ as normal BMI for the Japanese; $25 \mathrm{~kg} \mathrm{~m}^{-2}$ as upper limit of normal BMI range; and $27.5 \mathrm{~kg} \mathrm{~m}^{-2}$ as the mid-point of the overweight BMI range) were pre-specified before analyzing the data. In the comparison between candesartan and amlodipine, hazard ratios (HRs), 95\% confidence intervals (CIs) and $P$-values of the Wald test were also calculated with adjustment for age, sex, smoking history, hyperlipidemia, severe hypertension, cerebrovascular history, cardiac complications, renal dysfunction and antihypertensive drug use at baseline in the multivariate Cox regression model. Interactions of HRs between allocated drugs and the baseline variables of preexisting DM status and BMI (as continuous variable) were also evaluated in the multivariate Cox regression model with interaction terms. All statistical tests were two-sided and performed using SAS version 9.1 (SAS Institute, Cary, NC, USA).

\section{RESULTS}

Baseline characteristics and medication adherence

Of the 4703 patients that enrolled in the CASE-J trial, 2018 (42. 9\%) patients had DM at baseline and $2685(57.1 \%)$ did not. Table 1a summarizes the baseline characteristics by diabetic status at baseline and allocated drug. With regard to between-group comparisons, background characteristics were well balanced between both treatment groups except in regards to sex ratio and smoking history in patients without DM at baseline. The baseline characteristics of the BMI category were shown in Table $1 \mathrm{~b}$. There were some statistical differences in sex and current smoking history between two groups in the two BMI categories $\left(<22.0\right.$ and $\geqslant 25.0-<27.5 \mathrm{~kg} \mathrm{~m}^{-2}$, respectively), whereas there was no statistical difference in the BMI $\geqslant 27.5 \mathrm{~kg} \mathrm{~m}^{-2}$ category.

Percentages of patients who took more than $80 \%$ of the allocated drug and details regarding the distribution of additional drugs during the follow-up period have already been reported in the main results of the CASE-J trial. ${ }^{9}$ Regarding drug doses, $59.4 \%$ of patients in the candesartan group were taking $8 \mathrm{mg}$ at last follow-up, whereas $23.5 \%$ were taking $12 \mathrm{mg}$ and $13.8 \%$ were taking $4 \mathrm{mg}$. In the amlodipine group, $71.6 \%$ were taking $5 \mathrm{mg}$ at last follow-up, whereas $14.9 \%$ were taking $10 \mathrm{mg}$ and $9.5 \%$ were taking $2.5 \mathrm{mg}$. Mean doses in the candesartan and amlodipine groups were 8.3 and $5.6 \mathrm{mg}$, respectively.

\section{Association of diabetic status at baseline with the CASE-J trial outcome}

Over $3.3 \pm 0.8$ mean years of follow-up, primary CV events occurred in $103(3.8 \%)$ patients without DM at baseline (11.8 per 1000 patient-years) and in $165(8.2 \%)$ with $\mathrm{DM}$ at baseline (25.5 per 
Table 3 Hazard ratios for each event in patients with and without diabetes

\begin{tabular}{|c|c|c|c|c|c|c|c|c|c|c|c|}
\hline \multirow[b]{2}{*}{ Events } & \multicolumn{4}{|c|}{$D M(+)$ at baseline } & \multicolumn{4}{|c|}{ DM (-) at baseline } & \multicolumn{3}{|c|}{$D M(+)$ vs. $D M(-)$} \\
\hline & At risk & Events & Rate $^{a}$ & $95 \% \mathrm{Cl}$ & At risk & Events & Rate & $95 \% \mathrm{Cl}$ & $H R^{\mathrm{b}}$ & $95 \% \mathrm{Cl}$ & P-value \\
\hline Primary CV events & 2018 & 165 & 25.5 & $21.8-29.7$ & 2685 & 103 & 11.8 & $9.7-14.3$ & 2.58 & $2.00-3.33$ & $<0.001$ \\
\hline Cerebrovascular & 2018 & 54 & 8.2 & $6.1-10.7$ & 2685 & 57 & 6.5 & $4.9-8.4$ & 1.49 & $1.01-2.19$ & 0.044 \\
\hline Cardiac & 2018 & 67 & 10.2 & $7.9-12.9$ & 2685 & 23 & 2.6 & $1.7-3.9$ & 4.99 & $3.05-8.16$ & $<0.0001$ \\
\hline Renal & 2018 & 38 & 5.7 & $4.0-7.8$ & 2685 & 8.0 & 0.9 & $0.4-1.8$ & 7.44 & $3.47-16.22$ & $<0.0001$ \\
\hline Non-renal CV events & 2018 & 138 & 21.2 & $17.8-25.1$ & 2685 & 96 & 11.0 & $8.9-13.4$ & 2.34 & $1.78-3.08$ & $<0.001$ \\
\hline All-cause deaths & 2018 & 89 & 13.3 & $10.7-16.4$ & 2685 & 70 & 7.9 & $6.2-10.0$ & 2.04 & $1.46-2.87$ & $<0.001$ \\
\hline CV deaths & 2018 & 26 & 3.9 & $2.5-5.7$ & 2685 & 21 & 2.4 & $1.5-3.6$ & 1.93 & $1.03-3.61$ & 0.041 \\
\hline
\end{tabular}

Abbreviations: $\mathrm{Cl}$, confidence interval; $\mathrm{CV}$, cardiovascular; DM, diabetes mellitus; HR, hazard ratio.

aRate is expressed as incidence per 1000 patient-years.

bHR value was adjusted for the potential confounders (allocated drugs, age, body mass index, sex, severe hypertension, cerebrovascular history, cardiac complications, renal dysfunction, antihypertensive drug use at baseline, smoking history and hyperlipidemia).

Table 4 Comparisons between candesartan and amlodipine for each event for subgroups of diabetes status at baseline

\begin{tabular}{|c|c|c|c|c|c|c|c|c|c|c|c|c|}
\hline & \multicolumn{4}{|c|}{ Candesartan } & \multicolumn{4}{|c|}{ Amlodipine } & \multicolumn{3}{|c|}{ Comparison of treatment groups } & \multirow{2}{*}{$\frac{\text { Interaction test }}{\mathrm{P} \text {-value }}$} \\
\hline & At risk & Events & Rate $^{a}$ & $95 \% \mathrm{Cl}$ & At risk & Events & Rate $^{\mathrm{a}}$ & $95 \% \mathrm{Cl}$ & $H R^{\mathrm{b}}$ & $95 \% \mathrm{Cl}$ & $\mathrm{P}$-value & \\
\hline \multicolumn{13}{|c|}{ Primary CV events } \\
\hline $\mathrm{DM}(-)$ & 1343 & 54 & 12.5 & $9.4-16.3$ & 1342 & 49 & 11.2 & $8.3-14.8$ & 1.06 & $0.72-1.58$ & 0.744 & 0.565 \\
\hline $\mathrm{DM}(+)$ & 1011 & 80 & 24.8 & $19.6-30.8$ & 1007 & 85 & 26.3 & $21.0-32.5$ & 0.92 & $0.67-1.24$ & 0.568 & \\
\hline \multicolumn{13}{|c|}{ Cerebrovascular events } \\
\hline $\mathrm{DM}(-)$ & 1343 & 31 & 7.1 & $4.8-10.1$ & 1342 & 26 & 5.9 & $3.9-8.7$ & 1.13 & $0.67-1.90$ & 0.661 & 0.820 \\
\hline $\mathrm{DM}(+)$ & 1011 & 30 & 9.1 & $6.1-13.0$ & 1007 & 24 & 7.2 & $4.6-10.8$ & 1.22 & $0.71-2.10$ & 0.466 & \\
\hline \multicolumn{13}{|c|}{ Cardiac events } \\
\hline $\mathrm{DM}(-)$ & 1343 & 12 & 2.7 & $1.4-4.8$ & 1342 & 11 & 2.5 & $1.2-4.5$ & 1.12 & $0.49-2.57$ & 0.785 & 0.619 \\
\hline $\mathrm{DM}(+)$ & 1011 & 31 & 9.4 & $6.4-13.4$ & 1007 & 36 & 10.9 & $7.7-15.1$ & 0.87 & $0.54-1.40$ & 0.562 & \\
\hline \multicolumn{13}{|c|}{ Renal events } \\
\hline $\mathrm{DM}(-)$ & 1343 & 2 & 0.5 & $0.1-1.6$ & 1342 & 6 & 1.4 & $0.5-3.0$ & 0.31 & $0.06-1.57$ & 0.158 & 0.329 \\
\hline $\mathrm{DM}(+)$ & 1011 & 17 & 5.1 & $3.0-8.2$ & 1007 & 21 & 6.3 & $3.9-9.7$ & 0.72 & $0.38-1.37$ & 0.320 & \\
\hline \multicolumn{13}{|c|}{ Non-renal CV events } \\
\hline $\mathrm{DM}(-)$ & 1343 & 52 & 12.0 & $9.0-15.7$ & 1342 & 44 & 10.0 & $7.3-13.5$ & 1.16 & $0.77-1.73$ & 0.484 & 0.525 \\
\hline $\mathrm{DM}(+)$ & 1011 & 68 & 21.0 & $16.3-26.6$ & 1007 & 70 & 21.5 & $16.7-27.1$ & 0.97 & $0.70-1.36$ & 0.879 & \\
\hline \multicolumn{13}{|c|}{ All-cause deaths } \\
\hline $\mathrm{DM}(-)$ & 1343 & 33 & 7.5 & $5.1-10.5$ & 1342 & 37 & 8.4 & $5.9-11.5$ & 0.96 & $0.60-1.54$ & 0.853 & 0.775 \\
\hline $\mathrm{DM}(+)$ & 1011 & 40 & 11.9 & $8.5-16.3$ & 1007 & 49 & 14.7 & $10.8-19.4$ & 0.84 & $0.55-1.27$ & 0.407 & \\
\hline \multicolumn{13}{|l|}{ CV deaths } \\
\hline $\mathrm{DM}(-)$ & 1343 & 11 & 2.5 & $1.2-4.5$ & 1342 & 10 & 2.3 & $1.1-4.1$ & 1.13 & $0.48-2.68$ & 0.783 & 0.818 \\
\hline $\mathrm{DM}(+)$ & 1011 & 11 & 3.3 & $1.6-5.9$ & 1007 & 15 & 4.9 & $2.5-7.4$ & 0.78 & $0.36-1.71$ & 0.537 & \\
\hline
\end{tabular}

Abbreviations: $\mathrm{Cl}$, confidence interval; CV, cardiovascular; DM, diabetes mellitus; HR, hazard ratio.

aRate is expressed as incidence per 1000 patient-years.

bHR value was adjusted for the potential confounders (age, body mass index, sex, severe hypertension, cerebrovascular history, cardiac complications, renal dysfunction, antihypertensive drug use at

baseline, smoking history and hyperlipidemia).

1000 patient-years). Multivariate Cox regression analysis revealed that $\mathrm{DM}$ was an independent predictor of primary CV events (adjusted $\mathrm{HR}=2.58,95 \% \mathrm{CI}=1.99-3.33, P<0.0001$; Table 2), as were aging, cerebrovascular history, cardiac complications, renal dysfunction and antihypertensive drug use at baseline. In addition, DM was significantly associated with risk of each $\mathrm{CV}$ event and all-cause death (Table 3).
We then examined the effects of candesartan- and amlodipinebased regimens on the incidences of each event and all-cause deaths among subgroups of diabetic status at baseline, with analysis revealing no significant differences in event incidence between the two treatment regimens, regardless of diabetic status at baseline (Table 4). Newonset DM occurred in $38(2.8 \%)$ patients receiving candesartan-based regimens (8.7 per 1000 patient-years) and in 59 (4.4\%) receiving 
Table 5 Comparisons between candesartan and amlodipine for each event for BMI category at baseline

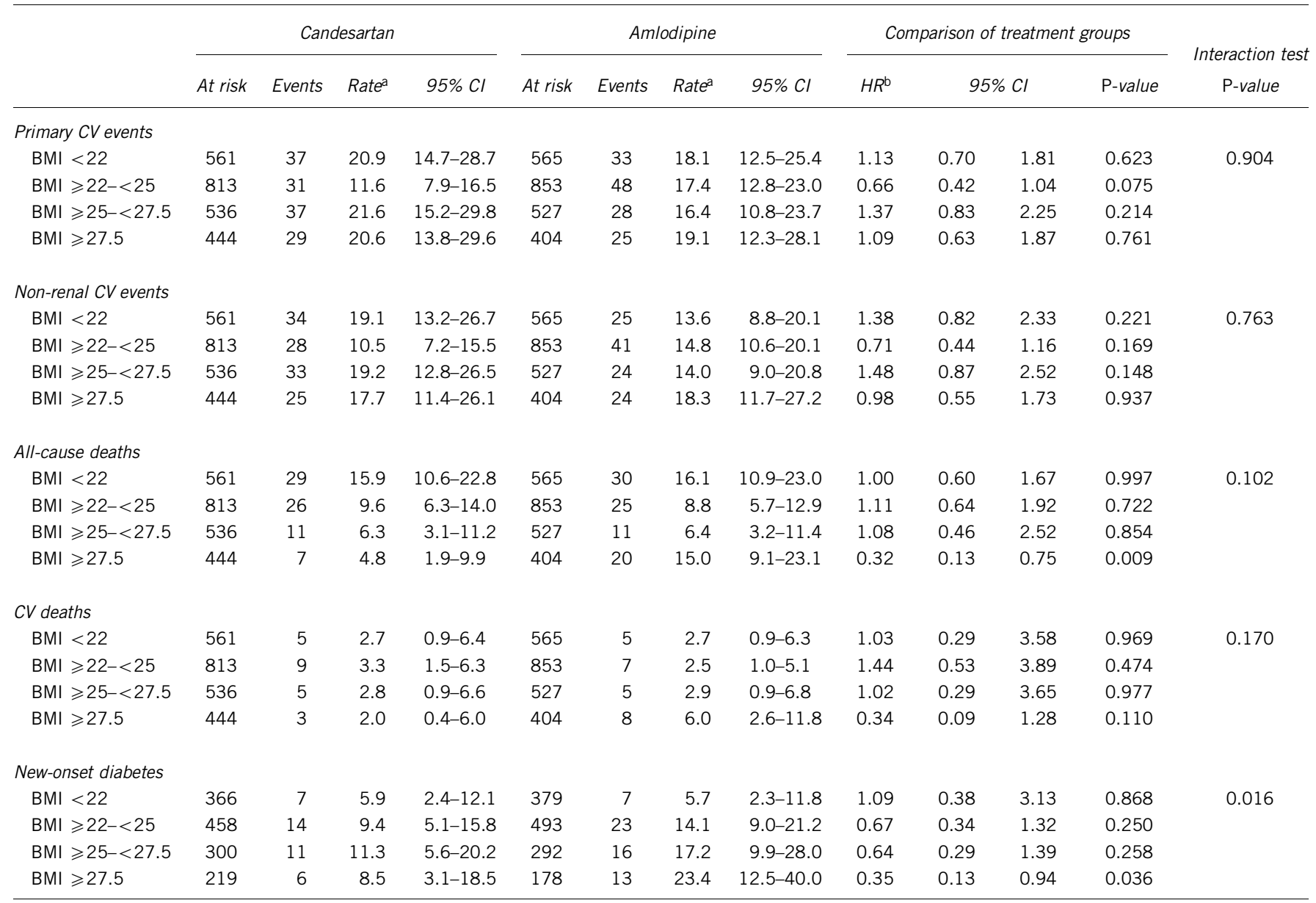

Abbreviations: $\mathrm{BMI}$, body mass index; $\mathrm{Cl}$, confidence interval; $\mathrm{CV}$, cardiovascular; $\mathrm{HR}$, hazard ratio.

a Rate is expressed as incidence per 1000 patient-years.

bHR value was adjusted for the potential confounders (age, diabetes mellitus, sex, severe hypertension, cerebrovascular history, cardiac complications, renal dysfunction, antihypertensive drug use at baseline, smoking history and hyperlipidemia).

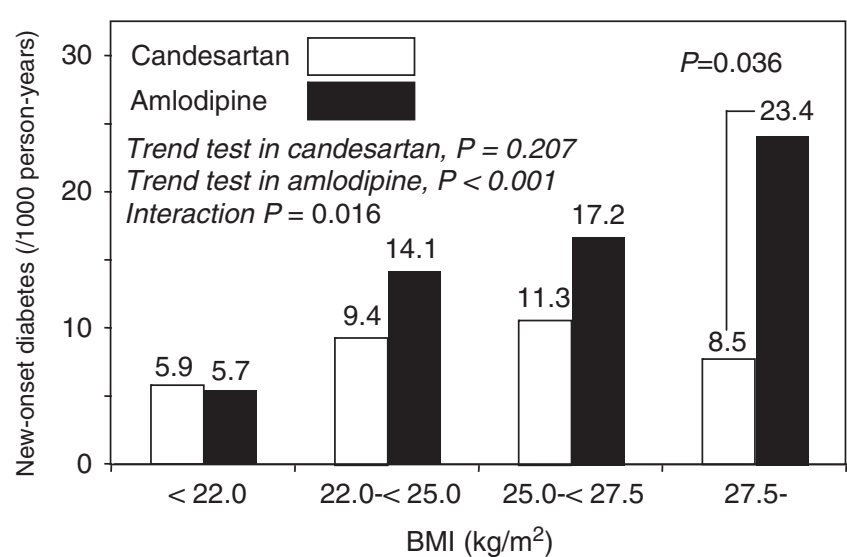

Figure 1 Relationship between new-onset diabetes and body mass index (BMI) at baseline.

amlodipine-based regimens (13.6 per 1000 patient-years). Multivariate Cox regression analysis also revealed that candesartan suppressed the incidence of new-onset DM to significantly greater degree than amlodipine (adjusted $\mathrm{HR}=0.66,95 \% \mathrm{CI}=0.43-0.99, P=0.043$ ). This adjusted HR was comparable with the unadjusted one reported previously. ${ }^{9}$

\section{Association of BMI at baseline with the CASE-J trial outcomes}

The actual number and incidence rate of primary CV events, nonrenal CV events, and all-cause death in each BMI category are shown in Table 5. No significant difference in incidence of primary and nonrenal CV events was noted between the two treatment regimens in any of the four BMI categories.

With regard to all-cause death, incidence in both regimens was most frequent in the lowest BMI category $\left(<22.0 \mathrm{~kg} \mathrm{~m}^{-2}\right)$. Incidence was similar between treatment regimen groups at BMI $<22.0 \mathrm{~kg} \mathrm{~m}^{-2}$; $22.0 \leqslant \mathrm{BMI}<25.0 \mathrm{~kg} \mathrm{~m}^{-2}$; and $25.0 \leqslant \mathrm{BMI}<27.5 \mathrm{~kg} \mathrm{~m}^{-2}$. However, a statistically significant difference was noted in the incidence among patients in the $\mathrm{BMI} \geqslant 27.5 \mathrm{~kg} \mathrm{~m}^{-2}$ category, with an adjusted HR of 0.32 (95\% $\mathrm{CI}=0.13-0.75, P=0.009)$. Furthermore, in this category, deaths from both CV (three in the candesartan group and eight in the amlodipine group) and non-CV causes (four in the candesartan group and 12 in the amlodipine group) were more frequent in the amlodipine group than in the candesartan group, although the number of events was small. 
Table 5 describes the number of patients with new-onset DM and the adjusted HRs in each category stratified according to BMI at study enrollment. In BMI subgroup analyses, candesartan significantly suppressed new-onset $\mathrm{DM}$ in the $\mathrm{BMI} \geqslant 27.5 \mathrm{~kg} \mathrm{~m}^{-2}$ category (adjusted $\mathrm{HR}=0.35,95 \% \mathrm{CI}=0.13-0.94, P=0.036$ ) compared with amlodipine. Figure 1 clearly shows that the increase in new-onset DM was dependent on BMI in the amlodipine group, whereas no such dependency was observed in the candesartan group, highlighting the statistically significant interaction between BMI and treatment group (interaction $P=0.016$ ).

\section{DISCUSSION}

In this analysis, we noted that DM was a strong risk factor for CV events among high-risk Japanese hypertensive patients, in addition to all-cause death, and other outcomes of the CASE-J trial. Furthermore, we showed that the ARB, candesartan, exerted a favorable effect in suppressing new-onset DM among patients with elevated BMI. However, no difference in occurrence of primary CV events was noted between candesartan and amlodipine groups regardless of diabetic status and BMI, albeit these findings had insufficient statistical power.

Previous studies that showed a decrease in the new-onset DM with antihypertensive treatment did not report the influence of BMI on the outcome. ${ }^{5,7}$ In our analysis, the incidence of new-onset DM was lower in patients with relatively low BMI than in those with relatively high $\mathrm{BMI}$ in the amlodipine group, suggesting that onset of DM is affected by the degree of patient obesity in this group. However, no such dependency was observed in patients receiving candesartan. When we conducted the additional post-hoc analysis with quintile cutoff points of the BMI category $(<21.6, \geqslant 21.6-23.4, \geqslant 23.4-<25.1, \geqslant 25.1-$ $<27.2$ and $\geqslant 27.2 \mathrm{~kg} \mathrm{~m}^{-2}$ ), the similar dependency was observed compared with that based on the pre-specified cutoff points of the BMI category (data not shown). These results suggested that candesartan reduced the new-onset DM by preventing the metabolically deleterious effects of increased adiposity in high-risk hypertensive patients.

The average BMI of participants in the CASE-J trial was approximately $25 \mathrm{~kg} \mathrm{~m}^{-2}$ among patients diabetic at enrollment and $24 \mathrm{~kg} \mathrm{~m}^{-2}$ among non-diabetic patients. As reported previously, ${ }^{9}$ patients with a BMI greater than or equal to $27.5 \mathrm{~kg} \mathrm{~m}^{-2}$, who were receiving candesartan had a significantly lower risk of all-cause death than those receiving amlodipine, whereas incidence of all-cause death was similar between the two treatment groups among patients occupying lower BMI strata. A U-shaped association between allcause death and BMI in a Japanese population has been previously reported, ${ }^{11}$ and this same relationship was also observed between allcause death and BMI among patients receiving amlodipine in this study. In contrast, no increase in all-cause death associated with increased BMI was observed for patients receiving candesartan (Table 5); results we interpret to indicate that candesartan treatment reduced the incidence of all-cause death among patients whose BMI was in the highest category, who might otherwise have suffered increased mortality.

The improvement in the insulin resistance observed under antihypertensive treatment has been attributed in part to the direct effect of reduced blood pressure on endothelial function. However, candesartan $^{12}$ and enalapril, ${ }^{13}$ both suppressed the development of DM in patients with congestive heart failure without hypertension, suggesting that the effect of RAS suppression on the development of DM is not necessarily a direct result of lowered BP. As angiotensinogen is produced by adipose tissue, ${ }^{14}$ and angiotensin II has a role in increasing insulin resistance through its effects on adipocyte function, ${ }^{15}$ the suppression of new-onset DM by candesartan may well depend on the state of adiposity and therefore be more profound in obese patients, as was observed in the present analysis. Hypertension and impaired glucose homeostasis associated with obesity can be considered a reflection of the pathophysiological process of metabolic syndrome. ${ }^{16-18}$ The suppression of both hypertension and glucose intolerance induced by candesartan in this study supports the hypothesis that RAS does indeed have a role in obesity and the development of metabolic syndrome, and results from this and previous studies will aid in development of treatment strategies for pathological conditions associated with obesity, such as metabolic syndrome.

Several limitations to this analysis warrant mention. First, our study was conducted as a post-hoc analysis, and therefore there was also a risk that our findings might occur by chance. Second, the number of patients in each subgroup may not have been sufficient to allow for a thorough examination of the relationship between DM (or BMI) and trial outcomes. Third, patients were not vigorously tested for the presence of DM at the end, and diagnosis of new-onset DM relied solely on the attending clinician's decision to prescribe anti-diabetic medications or a report of DM in the adverse event form. According to the National Diabetes Survey in 2002, 69.6\% of patients diagnosed as diabetic underwent either drug or insulin treatment. ${ }^{19}$ Therefore, although the number of new-onset DM as defined in this study may have underestimated the overall incidence of DM, it is highly probable that a considerable portion of new-onset DM cases were included in the results. Last, we cannot accurately claim that the decrease in new-onset DM observed in this study directly affected the overall CV morbidity and mortality of non-diabetic patients. The recent CASE-J Ex study ${ }^{20}$ may provide insights into these and other questions.

In conclusion, this analysis showed that DM increased CV risk among high-risk Japanese hypertensive patients. Candesartan treatment may produce significant suppression of all-cause death and reduced new-onset DM in patients with obesity. Results from this analysis will likely be of long-term benefit to obese hypertensive patients.

\section{CONFLICT OF INTEREST}

OT, NK, UK and ST have received honoraria for lectures from both Takeda Pharmaceutical and Pfizer Japan.

\section{ACKNOWLEDGEMENTS}

We thank all of the participants, physicians, medical staff and other contributors to the CASE-J trial. CASE-J trial was funded by EBM Research Center, Kyoto University of Graduate School of Medicine with unrestricted grant from Takeda Pharmaceutical and by the Japanese Society of Hypertension.

1 World Health Organisation, International Association for the Study of Obesity, International Obesity Taskforce. The Asia-Pacific Perspective: Redefining Obesity And Its Treatment. Health Communications Australia, Sydney, 2000.

2 Dahlöf B, Devereux RB, Kjeldsen SE, Julius S, Beevers G, de Faire U, Fyhrquist F, Ibsen $\mathrm{H}$, Kristiansson K, Lederballe-Pedersen O, Lindholm LH, Nieminen MS, Omvik P, Oparil S, Wedel H, LIFE Study Group. Cardiovascular morbidity and mortality in the losartan intervention for end point reduction in hypertension study (LIFE): a randomised trial against atenolol. Lancet 2002; 359: 995-1003.

3 Hansson L, Zanchetti A, Carruthers SG, Dahlöf B, Elmfeldt D, Julius S, Ménard J, Rahn $\mathrm{KH}$, Wedel $\mathrm{H}$, Westerling S. Effects of intensive blood-pressure lowering and low-dose aspirin in patients with hypertension: principal results of the hypertension optimal treatment (HOT) randomised trial. HOT study group. Lancet 1998; 351: 1755-1762. 
4 Tuomilehto J, Rastenyte D, Birkenhäger WH, Thijs L, Antikainen R, Bulpitt CJ, Fletcher AE, Forette F, Goldhaber A, Palatini P, Sarti C, Fagard R. Effects of calcium-channel blockade in older patients with diabetes and systolic hypertension. Systolic hypertension in Europe trial investigators. N Engl J Med 1999; 340: 677-684.

5 Niskanen L, Hedner T, Hansson L, Lanke J, Niklason A, CAPPP Study Group. Reduced cardiovascular morbidity and mortality in hypertensive diabetic patients on first-line therapy with an ACE inhibitor compared with a diuretic/beta-blocker-based treatment regimen: a subanalysis of the captopril prevention project. Diabetes Care 2001; 24: 2091-2096.

6 Blood Pressure Lowering Treatment Trialists' Collaboration. Effects of different blood pressure-lowering regimens on major cardiovascular events in individuals with and without diabetes mellitus - results of prospectively designed overviews of randomized trials. Arch Intern Med 2005; 165: 1410-1419.

7 Kjeldsen SE, Julius S, Mancia G, McInnes GT, Hua T, Weber MA, Coca A, Ekman S, Girerd X, Jamerson K, Larochelle P, MacDonald TM, Schmieder RE, Schork MA, Stolt P, Viskoper R, Widimskỳ J, Zanchetti A. Effects of valsartan compared to amlodipine on preventing type 2 diabetes in high-risk hypertensive patients: the VALUE trial. J Hypertens 2006; 24: 1405-1412.

8 Fukui T, Rahman M, Hayashi K, Takeda K, Higaki J, Sato T, Fukushima M, Sakamoto J, Morita S, Ogihara T, Fukiyama K, Fujishima M, Saruta T, CASE-J Study Group. Candesartan antihypertensive survival evaluation in Japan (CASE-J) trial of cardiovascular events in high-risk hypertensive patients: rationale, design, and methods. Hypertens Res 2003; 26: 979-990.

9 Ogihara T, Nakao K, Fukui T, Fukiyama K, Ueshima K, Oba K, Sato T, Saruta T, Candesartan Antihypertensive Survival Evaluation in Japan Trial Group. Effects of candesartan compared with amlodipine in hypertensive patients with high cardiovascular risks: CASE-J Trial. Hypertension 2008; 51: 393-398.

10 Japanese Society of Hypertension Guidelines Subcommittee for the Management of Hypertension. Guidelines for the management of hypertension for general practitioners. Hypertens Res 2001; 24: 613-634.

11 Tsugane S, Sasaki S, Tsubono Y. Under- and overweight impact on mortality among middle-aged Japanese men and women: a 10-y follow-up of JPHC study cohort I. Int J Obes (Lond) 2002; 26: 529-537.
12 Yusuf S, Ostergren JB, Gerstein HC, Pfeffer MA, Swedberg K, Granger CB, Olofsson B, Probstfield J, McMurray JV, Candesartan in Heart Failure-Assessment of Reduction in Mortality and Morbidity Program Investigators. Effects of candesartan on the development of a new diagnosis of diabetes mellitus in patients with heart failure. Circulation 2005; 112: 48-53.

13 Vermes E, Ducharme A, Bourassa MG, Lessard M, White M, Tardif JC, Studies Of Left Ventricular Dysfunction. Enalapril reduces the incidence of diabetes in patients with chronic heart failure: insight from the studies of left ventricular dysfunction (SOLVD). Circulation 2003; 107: 1291-1296.

14 Karlsson C, Lindell K, Ottosson M, Sjöström L, Carlsson B, Carlsson LM. Human adipose tissue expresses angiotensinogen and enzymes required for its conversion to angiotensin II. J Clin Endocrinol Metab 1998; 83: 3925-3929.

15 Zorad S, Fickova M, Zelezna B, Macho L, Kral JG. The role of angiotensin II and its receptors in regulation of adipose tissue metabolism and cellularity. Gen Physiol Biophys 1995; 14: 383-391.

16 National Cholesterol Education Program (NCEP) Expert Panel on Detection, and Evaluation, and Treatment of High Blood Cholesterol in Adults (Adult Treatment Panel III). Third Report of the National Cholesterol Education Program (NCEP) Expert Panel on Detection, Evaluation, and Treatment of High Blood Cholesterol in Adults (Adult Treatment Panel III) final report. Circulation 2002; 106: 3143-3421.

17 Miyawaki T, Hirata M, Moriyama K, Sasaki Y, Aono H, Saito N, Nakao K. Metabolic syndrome in Japanese diagnosed with visceral fat measurement by computed tomography. Proc Jpn Acad Ser B 2005; 81: 471.

18 Alberti KG, Zimmet P, Shaw J. Metabolic syndrome-a new world-wide definition. A consensus statement from the international diabetes federation. Diabetes Med 2006; 23: 469-480.

19 National Diabetes Survey. Ministry of health, labour and welfare. Accessed 14 April 2009 at http://www.health-net.or.jp/data/menu05/toukei/tonyo_h14.pdf, 2002.

20 Ueshima K, Oba K, Yasuno S, Fujimoto A, Sato T, Fukiyama K, Azuma J, Ogihara T, Saruta T, Nakao K, Candesartan Antihypertensive Survival Evaluation in Japan Trial Group. Long-term effects of candesartan and amlodipine on cardiovascular mortality and morbidity in Japanese high-risk hypertensive patients: Rationale, design, and characteristics of candesartan antihypertensive survival evaluation in Japan extension (CASE-J Ex). Contemp Clin Trials 2009; 30: 97-101. 